\title{
Sporadic breast cancer among relatives of BRCA mutation carriers
}

\section{To the Editor:}

The development of breast cancer is a multistep process with many factors contributing to malignant transformation. Even among carriers of BRCA mutations, not all subjects will develop breast cancer, ${ }^{1}$ and environmental and hormonal factors may determine whether cancer will develop. ${ }^{2-4}$ Family members who are not carriers may be exposed to the same environmental factors, which may impact on the development of sporadic cancer as well. Breast cancer associated with a BRCA mutation often develops at a young age and is more often bilateral than sporadic breast cancer. ${ }^{5,6}$ Sporadic cancer among relatives of BRCA mutation carriers has not been well studied. Relatives of BRCA mutation carriers who are not found to be carriers themselves are generally counseled that their risk of developing breast cancer is no different than that of a woman without a family history of the disease. However, with breast cancer being one of the most common cancers in much of the Western world, the risk of developing breast cancer without carrying a genetic mutation is still substantial.

We searched our clinical oncogenetics database of 1061 Ashkenazi Jewish female patients with breast cancer who were tested for all three Ashkenazi BRCA1 and BRCA2 founder mutations (165delAG, 5382insC, and 6174delT). A complete family history was available for all patients, and genetic counseling and testing were routinely recommended for all first-degree relatives of patients found to be carriers. We sought families in 
whom a patient with breast cancer was a carrier of a known BRCA mutation and in whom a first-degree relative was not a carrier but nevertheless developed breast cancer.

Eight families $(0.75 \%)$ were identified (four pairs of sisters, three pairs of mother and daughter, and a father and daughter) in whom one was an affected carrier of a BRCA mutation and the other had breast cancer but was not a carrier. These cases are summarized in Table 1. A pedigree of one such family is depicted in Figure 1.

Remarkably, younger age at the time of diagnosis was not associated with carrier status among pairs of relatives. The average age at which breast cancer was diagnosed was 48.8 years for the carriers (range 36-77 years) and 44.3 years for the noncarriers (range 27-60 years). (Only age at first diagnosis was used for calculation.) In fact, breast cancer developed at a younger age in noncarriers in six of the eight families.

We conclude that the presence of a mutation in a family should not lead to the assumption that all breast cancers in that family, including in young women, are caused by the same mutation and that every patient should be tested to determine her carrier status.

The possibility that a relative may carry a different nonfounder mutation, although possible, is remote. Among Ashkenazi Jews, breast cancer related to mutations other than the known Ashkenazi Jewish founder mutations is rare and, al-

\section{Table 1}

First-degree relatives of BRCA mutation carriers who developed sporadic breast cancer

\begin{tabular}{|c|c|c|c|c|}
\hline Family & Relative & BRCA & $\begin{array}{c}\text { BRCA } \\
\text { Mutation }\end{array}$ & $\begin{array}{c}\text { Age at } \\
\text { diagnosis }\end{array}$ \\
\hline \multirow[t]{3}{*}{1} & Sister & negative & negative & 49 \\
\hline & Daughter/niece & negative & negative & 32 \\
\hline & Sister & positive & 5382insC & 41,57 \\
\hline \multirow[t]{2}{*}{2} & Sister & negative & negative & 32 \\
\hline & Sister & positive & $6174 \mathrm{delT}$ & 42 \\
\hline \multirow[t]{2}{*}{3} & Sister & negative & negative & 42 \\
\hline & Sister & positive & 6174delT & 62 \\
\hline \multirow[t]{2}{*}{4} & Sister & negative & negative & 49 \\
\hline & Sister & positive & 6174delT & 51 \\
\hline \multirow[t]{3}{*}{5} & Daughter/niece & negative & negative & 27 \\
\hline & Father & positive & 6174delT & healthy \\
\hline & Paternal aunt & positive & 6174delT & 36 \\
\hline \multirow[t]{2}{*}{6} & Daughter & negative & negative & 60 \\
\hline & Mother & positive & 185delAG & 77 \\
\hline \multirow[t]{2}{*}{7} & Mother & negative & negative & 60 \\
\hline & Daughter & positive & 6174delT & 39 \\
\hline \multirow[t]{2}{*}{8} & Mother & negative & negative & 48,60 \\
\hline & Daughter & positive & 185delAG & 42 \\
\hline
\end{tabular}

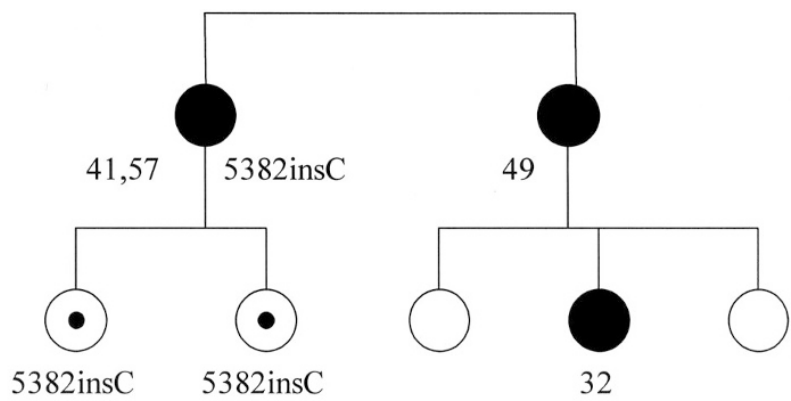

Breast cancer

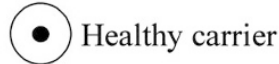

Figure 1. Pedigree of a family with two sisters and a daughter/niece who developed breast cancer before the age of 50 years (family no. 1 in Table 1). One sister, who developed bilateral breast cancer at 41 years of age and then at 57 years of age, was a carrier of a BRCA1 mutation. The other sister and her daughter, who also developed breast cancer at a young age, had none of the known BRCA mutations or any mutation on sequencing of both BRCA genes. Numbers indicate age at time of breast cancer diagnosis.

though reported in $21.6 \%$ of Ashkenazi Jews who underwent full-sequence analysis of BRCA 1 and 2,7 unlikely to coexist in a family with a known founder mutation. We recently sequenced samples from 40 patients with breast cancer who had a family history of breast cancer or developed breast cancer at a young age, and found a nonfounder mutation in two patients (5\%) (Abeliovich, $\mathrm{PhD}$, unpublished, 2004).

Further study should be conducted to determine the prevalence and risk of sporadic breast cancer among relatives of mutation carriers, and the clinical and pathologic characteristics of those cancers. In addition, attention needs to be directed to hormonal and environmental factors, which may be related to breast cancer among relatives with BRCA-associated and sporadic breast cancer.

Tanir M. Allweis, MD

Michal Sagi, PhD

Tamar Peretz, MD

Hadassah Hebrew University Medical Center Jerusalem, Israel

\section{References}

1. Struewing JP, Hartge P, Wacholder S, Baker SM, et al. The risk of cancer associated with specific mutations of BRCA1 and BRCA2 among Ashkenazi Jews. N Engl J Med 1997;336(20):1401-1408.

2. Jernstrom H, Lubinski J, Lynch HT, Ghadirian P, et al. Breast-feeding and the risk of breast cancer in BRCA1 and BRCA2 mutation carriers. J Natl Cancer Inst 2004;96(14):1094-1098.

3. Narod SA, Dube MP, Klijn J, Lubinski J, et al. Oral contraceptives and the risk of breast cancer in BRCA1 and BRCA2 mutation carriers. J Natl Cancer Inst 2002;94(23):1773-1779.

4. Jernstrom H, Lerman C, Ghadirian P, Lynch HT, et al. Pregnancy and risk of early breast cancer in carriers of BRCA1 and BRCA2. Lancet 1999;354(9193):1846-1850.

5. Metcalfe K, Lynch HT, Ghadirian P, Tung N, et al. Contralateral breast cancer in BRCA1 and BRCA2 mutation carriers. J Clin Oncol 2004 15;22(12):2328-2335.

6. Tryggvadottir L, Olafsdottir EJ, Gudlaugsdottir S, Thorlacius S, et al. BRCA2 mutation carriers, reproductive factors and breast cancer risk. Breast Cancer Res 2003;5: (5)R121-R128. Epub 2003 Jun 24.

7. Frank TS, Deffenbaugh AM, Reid JE, Hulick M, et al. Clinical characteristics of individuals with germline mutations in BRCA1 and BRCA2: analysis of 10,000 individuals. J Clin Oncol 2002;20(6):1480-1490. 